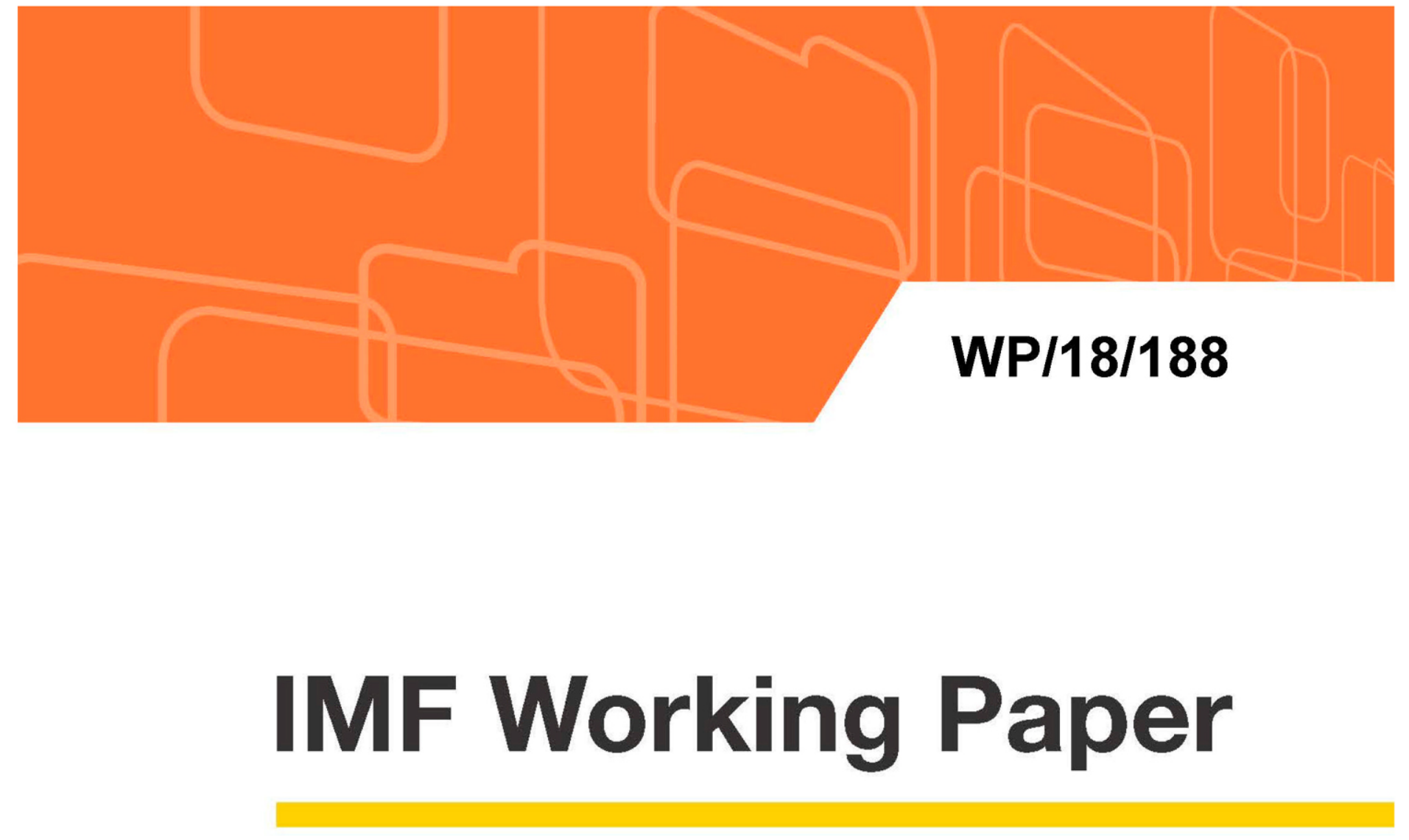

\title{
Understanding Euro Area Inflation Dynamics: Why So Low for So Long?
}

by Yasser Abdih, Li Lin, and Anne-Charlotte Paret

IMF Working Papers describe research in progress by the author(s) and are published to elicit comments and to encourage debate. The views expressed in IMF Working Papers are those of the author(s) and do not necessarily represent the views of the IMF, its Executive Board, or IMF management.

$$
\text { I N T E R N A T I O N A L M O N E T A R Y F U N D }
$$




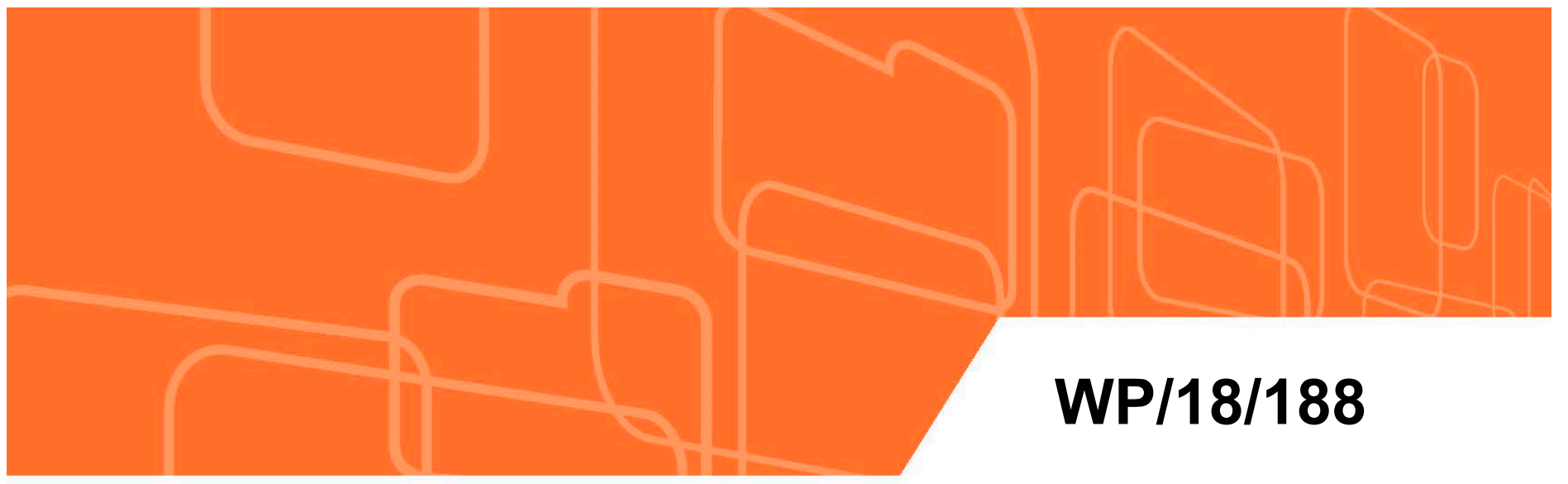

\section{IMF Working Paper}

\section{Understanding Euro Area Inflation Dynamics: Why So Low for So Long?}

by Yasser Abdih, Li Lin, and Anne-Charlotte Paret

IMF Working Papers describe research in progress by the author(s) and are published to elicit comments and to encourage debate. The views expressed in IMF Working Papers are those of the author(s) and do not necessarily represent the views of the IMF, its Executive Board, or IMF management.

$$
\text { I N T E R N A T | O N A L M O N E T A R Y F U N D }
$$




\title{
IMF Working Paper
}

\author{
European Department
}

\section{Understanding Euro Area Inflation Dynamics: Why So Low for So Long? Prepared by Yasser Abdih, Li Lin, and Anne-Charlotte Paret ${ }^{1}$}

Authorized for distribution by Shekhar Shankar Aiyar

August 2018

\section{IMF Working Papers describe research in progress by the author(s) and are published to elicit comments and to encourage debate. The views expressed in IMF Working Papers are those of the author(s) and do not necessarily represent the views of the IMF, its Executive Board, or IMF management.}

\begin{abstract}
Despite closing output gaps and tightening labor markets, inflation has remained low in the euro area. Based on an augmented Phillips Curve framework, we find that this phenomenon - sometimes attributed to low global inflation - has been primarily caused by a remarkable persistence of inflation, keeping it low despite the reduction in slack. This feature is shown to be specific to the euro area (in comparison with the United States). Monetary policy needs to stay accommodative to help guide inflation back to target.

JEL Classification Numbers: E10, E31, E32, E37, E52, C22, C50

Keywords: Inflation, Phillips curve, inflation persistence and expectations Author's E-Mail Address: yabdih@imf.org, 1lin@imf.org, aparet-onorato@imf.org

\footnotetext{
${ }^{1}$ The authors are grateful to Shekhar Aiyar, Bergljot Barkbu, Nigel Chalk, Rishi Goyal, Plamen Iossifov, Alvar Kangur, Daniel Leigh, Mahmood Pradhan, Mehdi Raissi, Anke Weber, IMF reviewers and participants in the IMF surveillance meetings and the IMF 2018 Spring Meetings Analytical Corner presentations as well as in presentations at the European Central Bank and German Ministry of Finance for their helpful comments and support. We thank Xiaobo Shao for excellent research assistance.
} 


\section{CONTENTS}

ABSTRACT

I. INTRODUCTION __ $\underline{3}$

II. EMPIRICAL ANALYSIS

A. Can a Global Phillips Curve Solve the Inflation Puzzle? __

B. Which Domestic Factors Help to Solve the Inflation Puzzle?

III. DISCUSSION

A. On the Role of Global Factors

B. Possible Drivers of Stickier Inflation in the Euro Area (Compared to the U.S.) __

C. On the Anchoring of Inflation Expectations ___

IV. POLICY IMPLICATIONS AND CONCLUSION __ $\underline{18}$

V. APPENDIX _ $2 \underline{20}$

VI. REFERENCES __ 22 


\section{Introduction-The Inflation Puzzle And Possible Explanations}

1. Euro area inflation has been below the European Central Bank's (ECB) inflation objective since 2013, adjusting very slowly to tightening labor market conditions.

Tremendous efforts have been spent by the ECB to guide inflation to the objective of close to, but below 2 percent. These included lowering the policy rate to zero and carrying out a range of unconventional monetary policies, such as the negative deposit rate and asset purchases. These efforts have underpinned the recovery, with unemployment rate declining from the peak of 12.1 percent in 2013 to 8.5 percent by Q2 2018 and more than 7.5 million jobs being created. However, inflation has responded to policy efforts only to a lesser extent. As of June 2018, the less volatile core inflation measures were still below 1.5 percent, even though the remaining unemployment was estimated as being mostly structural.

Euro area inflation has been below ECB's objective since 2013, and wage growth remained subdued.

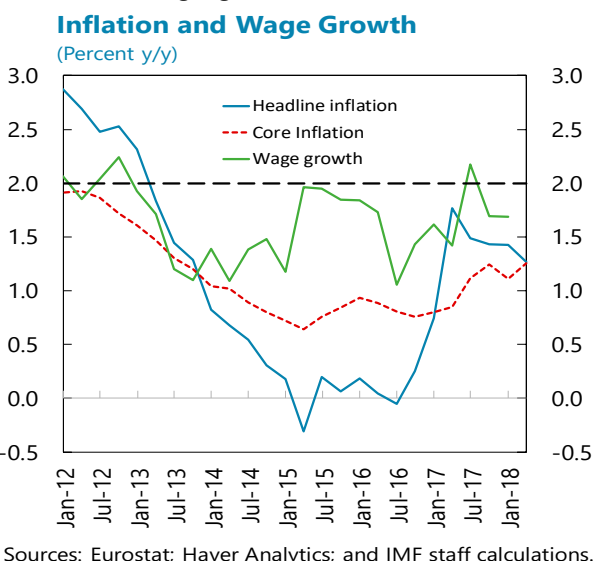

The persistently low inflation seems at odds with the steady job creations and the continued...

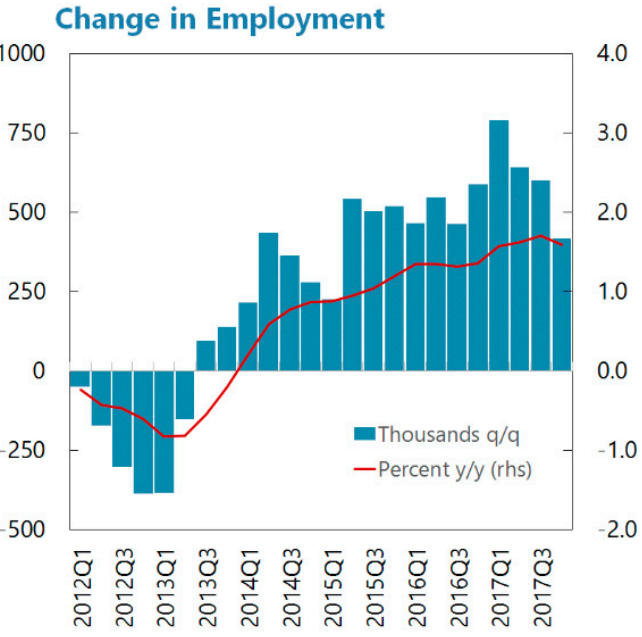

Sources: Eurostat; Haver Analytics; WEO; and IMF staff calculations.

\section{Figure 1}

This occurred despite the unprecedented loosening of monetary conditions.

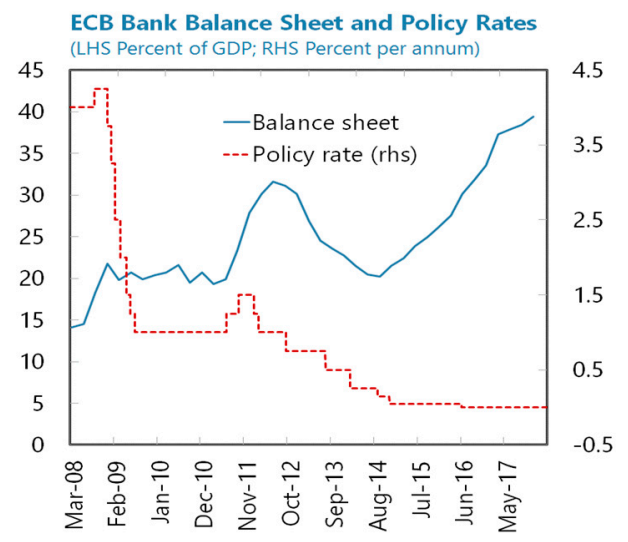

Sources: Haver Analytics and IMF staff calculations. ...decline in the unemployment rate. The remaining unemployment is mostly structural as of early 2018.

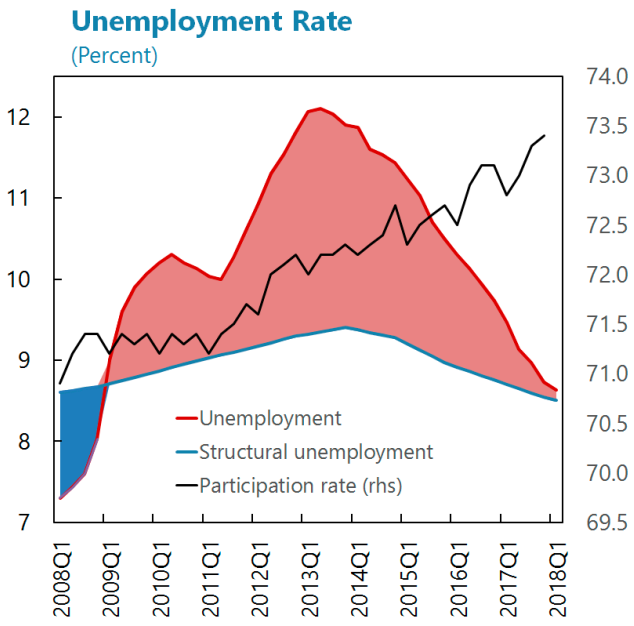

Sources: Eurostat; Haver Analytics; WEO; and IMF staff calculations. 
2. The seemingly decoupling of euro area inflation and labor market developments arose in 2012. Figure 2 shows the euro area core inflation together with the unemployment gap. Over the period of 2000Q1 to 2011Q4, there appeared to be a well-established Phillips curve (in green, i.e., a negative relationship between inflation and domestic economic slack). However, since 2012, an inflation puzzle emerged. First there was a "missing disinflation" episode over the two years starting early 2012, with inflation reacting slowly to higher unemployment rates (in blue). Thereafter followed a "missing inflation" period (in yellow), with inflation being remarkably stable despite considerable declines in the unemployment rate.

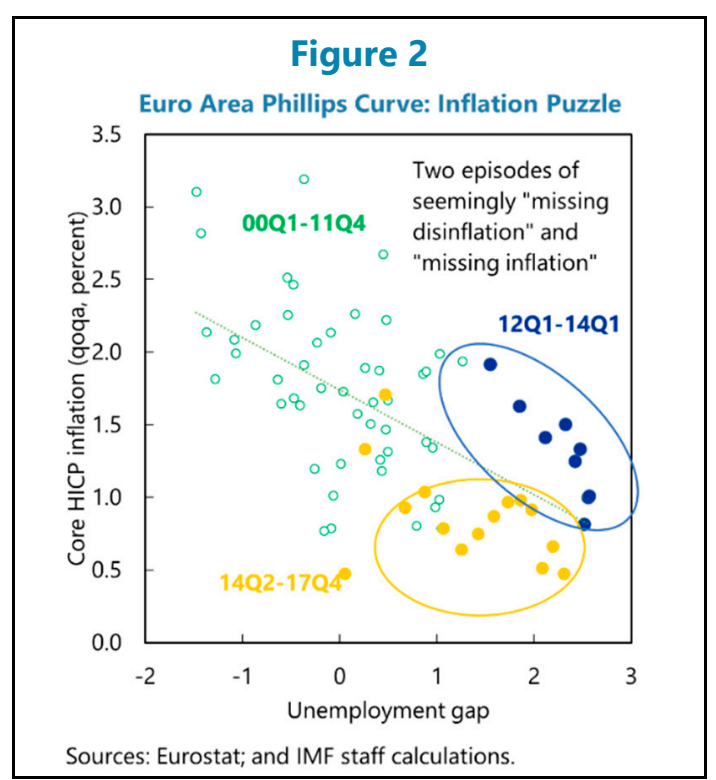

3. Some attribute the weakened Phillips curve to the globalization of inflation. A few recent publications (e.g., Carney, 2017, Auer et al., 2017) suggest that the Phillips curve may have become more global. Low global inflation may have brought low inflation to the euro area through cheaper imports. As a result, the link between domestic slack and domestic inflation would be weakened, and domestic and global inflation would move closely together (Figure 3, LHS). Moreover, the close integration of trade in goods and services, especially through global value chains, may have caused high synchronization between foreign and domestic business cycles (Figure 3, RHS), further reducing the link between domestic slack and domestic inflation, and reinforcing the co-movement of domestic and foreign inflation.

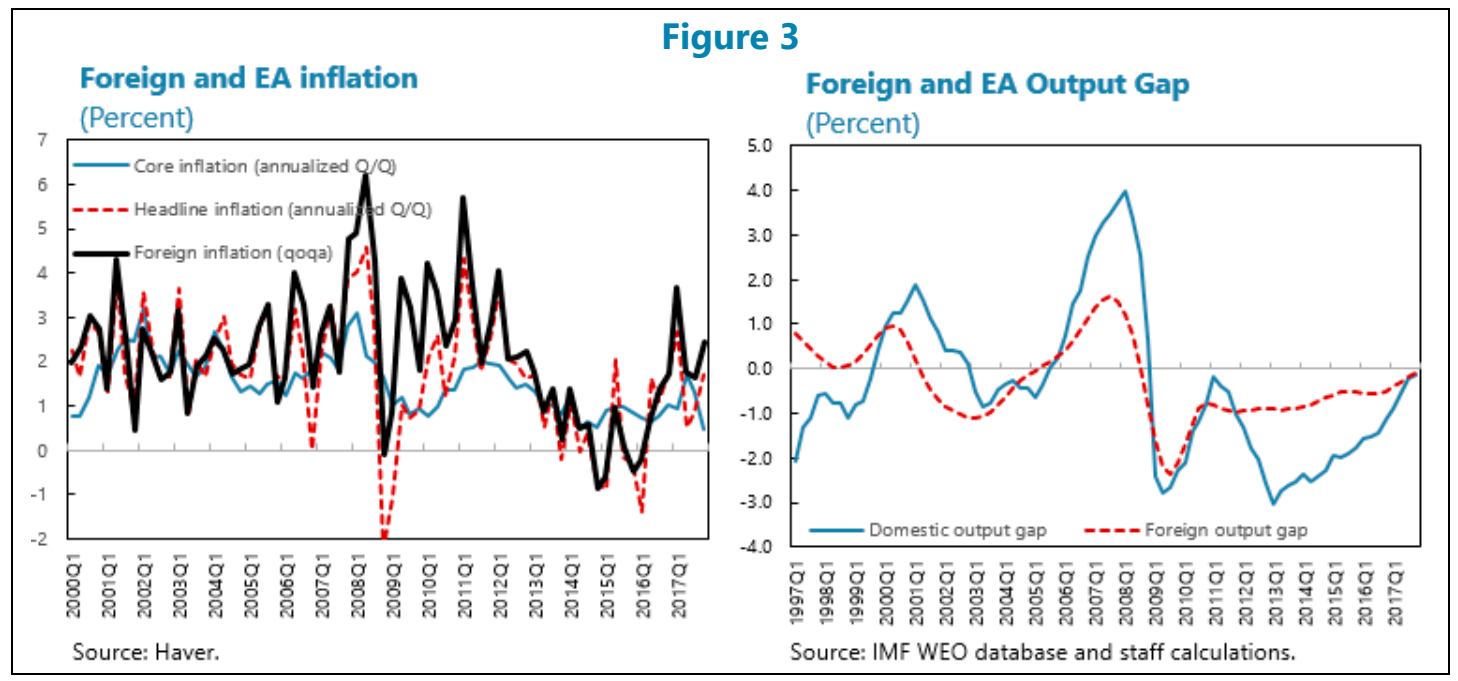

4. An analysis is needed, however, to understand whether the origin of low inflation in the euro area is domestic or global. The deeper economic downturn in the euro area since 2012, compared with the rest of the world (Figure 3), and the associated lower domestic inflation suggest that domestic factors are important in shaping euro area inflation developments in recent years. Moreover, in the euro area, service inflation, which is likely 
more influenced by domestic factors, declined by more than goods inflation, which is likely more influenced by global factors, after the global financial crisis, suggesting a dominating role for domestic factors (Figure 4). ${ }^{2}$

5. Impacts of other global/external factors, including exchange rate and oil prices, are also worth considering. The nominal effective exchange rate of the euro appreciated by 2.1 percent $(y / y)$ over 2017, and has further appreciated by about

3.2 percent in 2018Q1, compared with the 2017 average. Even though the appreciation appears to mostly reflect better-than-expected economic activities relative to trading partners (IMF, 2017a) and hence is expected to have limited negative

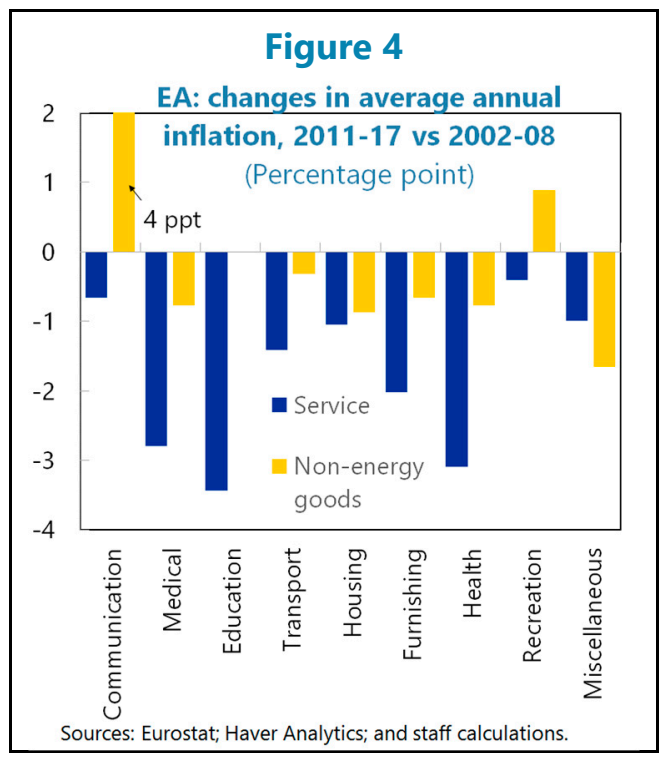
effects on inflation, it nevertheless could delay the process of upward adjustment of inflationary pressures. Oil price and non-oil import prices had a downturn between 2014 and 2016, which could help explain the low inflation in the euro area during this period.

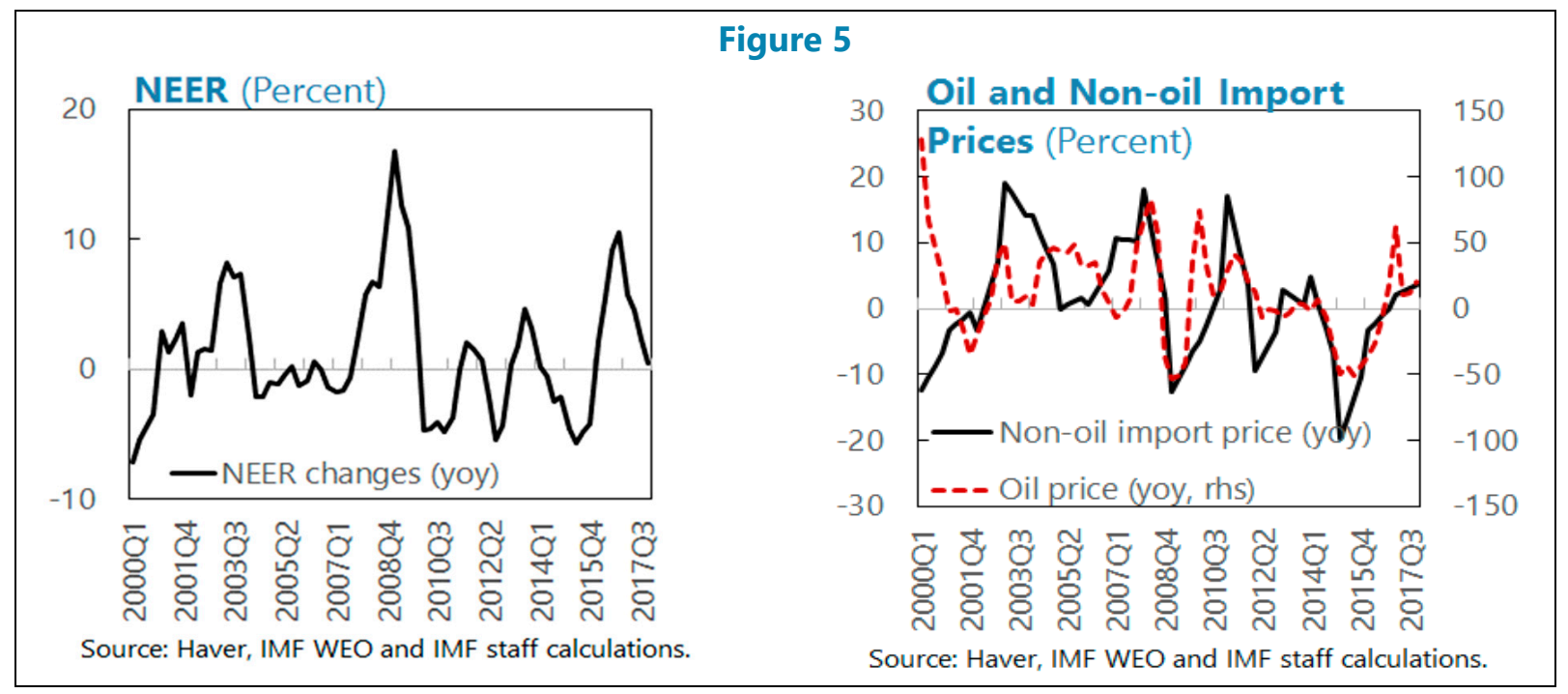

6. This paper introduces the above-discussed global factors into a standard expectation-augmented Phillips curve to understand the drivers of euro area inflation. We focus on core measures that exclude volatile food and energy prices. We start with a typical New-Keynesian style Phillips curve (Gali and Gertler, 1999), where core inflation is a function of forward-looking inflation expectations and a measure of economic slack. Based on this framework, we assess the ability of several global factors to enhance the model's

${ }^{2}$ This suggests that, for future research, core goods and core services inflation could be modeled separately and then used to form a composite forecast for overall core inflation. The latter could be assessed against the forecast obtained from the aggregate Phillips curve. 
forecast performance and explain the recent low inflation episode. ${ }^{3} \mathrm{We}$ then assess the robustness of our model to different measures of inflation expectations and economic slack.

7. Importantly, we take into account the persistence in the inflation process. If inflation is persistent, the transition process after being hit by a negative inflation shock will be longer. This will delay the upward adjustment of inflation, even if economic activity improves, making the "Phillips curve" look flat (i.e., less responsive to economic developments). Over the period 1999Q1 through 2017Q4, the simple correlation of core inflation in the euro area with its first own lag is about 0.8 and still about 0.3 with the fifth lag (Figure 6), suggesting a highly persistent process. Moreover, inflation has been more inertial in the euro area than in the United States, as noted in ECB (2011).

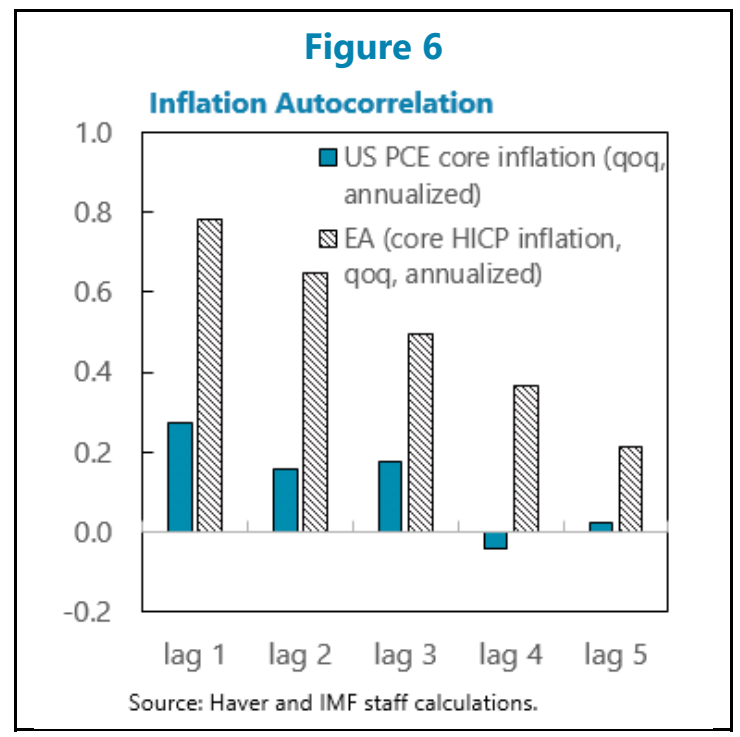

8. We find that domestic factors dominate global factors in explaining recent inflation dynamics. Using the General-to-Specific model selection procedure (more details in Section II), the preferred specification is a domestic Phillips curve including lagged inflation, long-term inflation expectations and domestic slack. Even though some models with global factors have better out-of-sample forecast performance, they do not clearly enhance the model's in-sample fit. Besides, a decomposition of inflation drivers shows that global factors are economically less meaningful in explaining inflation developments, as opposed to domestic factors. Lastly, global factors do not help to explain the recent low inflation episode.

9. The domestic Phillips curve can explain the puzzle, with inflation persistence being the key factor behind recent low inflation. The relationship between slack and inflation holds and is robust to different measures of slack and the addition of global factors. Importantly, euro area inflation is highly persistent, delaying the responsiveness of inflation to changes in underlying economic activities. We also find the inflation process to be much more backward-looking in the euro area than in the U.S. The causes for the persistence are beyond the scope of the analysis, but could be linked to sluggishness at various stages of the transmission from labor market developments to prices (namely linked to wage dynamics and price setting specificities). Some of them are mentioned in Section III.B.

10. The empirical evidence is mixed on whether low inflation and wage growth could be explained by unmeasured labor market slack. As laid out in ECB (2017a), the unemployment rate may not fully capture the amount of slack in the labor market, as it does

\footnotetext{
${ }^{3}$ A number of global factors are considered, namely foreign output gap, foreign inflation, non-oil import prices, oil prices and the nominal effective exchange rate.
} 
not capture the underutilization of labor due to discouraged workers or involuntary part-time work. These factors could also partially explain low inflation in advanced economies, including the euro area (IMF, 2017b), and the low wage growth in advanced Europe (IMF, 2018). ${ }^{4}$ In the case of the euro area, a broader labor market indicator incorporating those that are underemployed and marginally attached to the labor force shows a larger degree of "nonemployment" in the economy than the unemployment rate (Figure 7). However, this may not constitute additional slack as the additional source of "non-employment" seems to be mainly structural.

Figure 7

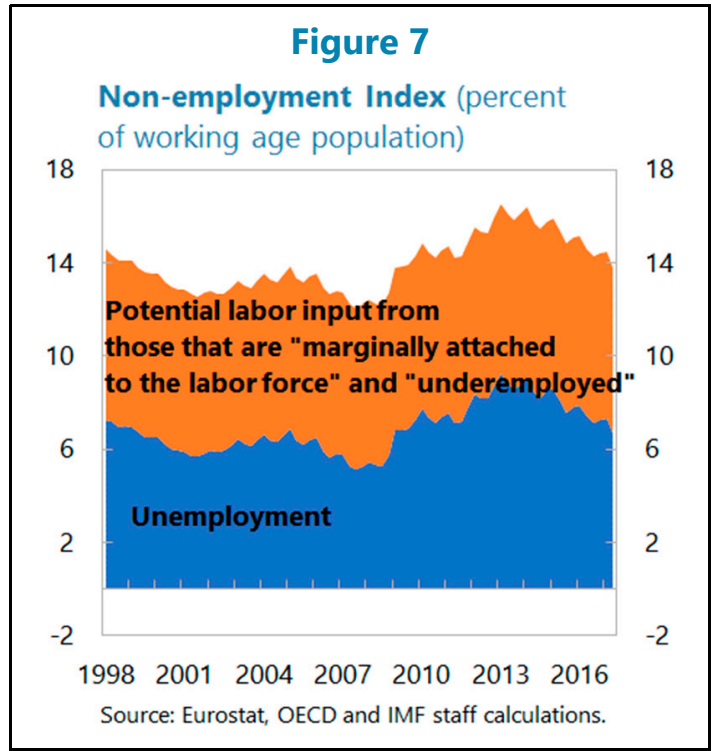

11. The remainder of the paper is organized as follows. Section II details the methodology and the results of the different Phillips curve estimates. Section III discusses the results, in the light of ongoing debates. Section IV draws some policy implications and concludes.

\section{EMPIRICAL ANALYSIS}

12. Our analysis focuses on euro area-wide core inflation, measured by headline inflation excluding energy and unprocessed food. Core inflation provides "information about the medium-term "attractor" to which headline inflation will gravitate once short-term shocks have faded out" (ECB, 2018). Besides, we focus on aggregate core inflation for the euro area, and do not investigate country-specific features, which are left for future research.

\section{We run a horse race between several global factor-augmented Phillips curve} specifications. Starting from a domestic Phillips curve, we augment it with different types of global factors, so as to assess their importance in explaining inflation dynamics. In the second step, we examine the fit of the Phillips curve with alternative measures for economic slack and inflation expectations. As mentioned above, we allow inflation to be partly backward-looking, consistent with the widely observed persistence of inflation. The general specification for the first step is the following:

$$
\pi_{t}=\gamma(L) \pi_{t}+\mu \pi_{t+5 \text { years }(S P F)}^{e}+\alpha(\mathrm{L}) \tilde{u}_{t}+\beta(\mathrm{L}) X_{t}+\epsilon_{t}
$$

\footnotetext{
${ }^{4}$ Abdih and Danninger (2018) find that the contribution of the unemployment gap to wage growth in the U.S. is broadly the same whether one measures unemployment by the headline number or by a broader measure that incorporates individuals marginally attached to the labor force (including discouraged workers) and people working part time but would prefer full-time jobs.
} 
with $\pi_{t}$ being the euro area annualized Q/Q core inflation, $\pi_{t+5 \text { years (SPF) }}^{e}$ the current fiveyear ahead survey inflation expectations, $\tilde{u}_{t}$ the unemployment gap, and $X_{t}$ a vector of global variables including non-oil import prices, oil prices inflation, foreign inflation, foreign output gap and/or NEER growth. ${ }^{5}$ The first three factors comprise the standard domestic part of the Phillips curve, whereas the others are global factors potentially driving inflation dynamics. The general specification allows up to eight lags for the NEER and up to four lags for all other variables.

\section{A. Can a Global Phillips Curve Solve the Inflation Puzzle?}

\section{In this section, we examine whether global factors can help explain the currently low inflation rates in the euro area. We mainly follow two steps:}

- The General-to-Specific methodology (Campos, Ericsson and Hendry, 2005, henceforth GTS) helps find the most relevant global variables, based on the in-sample period of 1999Q1-2015Q4. ${ }^{6}$ Starting from a general unrestricted model (GUM), this methodology sequentially removes non-statistically significant variables and lags to reduce the initial unrestricted model and select a final (parsimonious) model. ${ }^{7}$ Since there are multiple measures of global variables with a relatively high degree of collinearity, we first augment the domestic Phillips curve with global factors one at a time. We therefore have five GUMs, each with a different global variable: non-oil import prices, oil prices, foreign inflation, foreign output gap, or the exchange rate. As the exchange rate evolves relatively independently from other global variables, we also run four additional GUMs including the exchange rate and one additional global variable, each at a time. Together, we run nine versions of GUMs through the GTS procedure.

- In the next step, we run a "horse race" with the nine versions of global Phillips curves generated by the GTS procedure and a purely domestic Phillips curve. While the GTS procedure results in selecting the global variables that best explain past inflation (those being significant enough to be selected in the reduced models), the comparison of the models' out-of-sample forecast performances helps us to further select the most useful ones to predict inflation developments.

\footnotetext{
${ }^{5}$ More precisely, the euro area annualized Q/Q core inflation is assumed to be a function of its own lags, current 5-year ahead survey inflation expectations (from the ECB survey of professional forecasters), as well as current and past values of the unemployment gap (the unemployment rate less an estimate of its natural rate). For the global variables we use the foreign output gap and annualized Q/Q growth of non-oil import prices, oil prices, foreign prices, and of the NEER. We also experiment with expressing import and oil prices relative to lagged core CPI; the results, though, are very similar to those reported in the paper.

${ }^{6}$ For an application of the General-to-Specific methodology to estimating Phillips curves for the U.S., see Abdih et. al. (2016).

${ }^{7}$ The procedure uses F-tests and information criteria (Schwartz criterion) to allow for lag reduction and sequentially remove insignificant variables and lags. The procedure ensures that the final model is not pathdependent (i.e., the order in which insignificant variables are dropped does not change the results) and that statistical tests that are passed in the GUM are passed also in the reduced model.
} 
15. These results are shown in Figure 8. Blue bars correspond to specifications where global variables are selected by the GTS procedure (i.e., where the global factor is considered useful to explain inflation dynamics), while white bars correspond to specifications where no global variable has been selected in the final model. Moreover, each bar illustrates the rootmean-squared-error (RMSE) of the final reduced model resulting from the GTS procedure. The lower the RMSE, the better the out-of-sample fit. The dotted line corresponds to the RMSE of a purely domestic Phillips curve, which is our benchmark. A model that outperforms the domestic Phillips curve will have an RMSE lower than this threshold.

\section{At a first pass, the exchange rate, non-oil import prices and foreign inflation appear to be useful in explaining core inflation dynamics (Figure 9). Oil prices and the} foreign output gap, however, are not selected in the reduced model (see white bars in Figure 8). Among the rest of the specifications with global variables (i.e., the blue bars in Figure 8), only three have comparable or better out-of-sample forecast performance than the domestic Phillips curve. One of the specifications includes the exchange rate as the only global variable, while the other two include the exchange rate together with either the non-oil import prices or foreign inflation. Table 1 provides the estimates of these specifications, under the heading "Global Phillips curves."

Figure 8. Forecast Performance of Global Factor Augmented Phillips Curve Models, for the Period 2016Q1-2017Q4

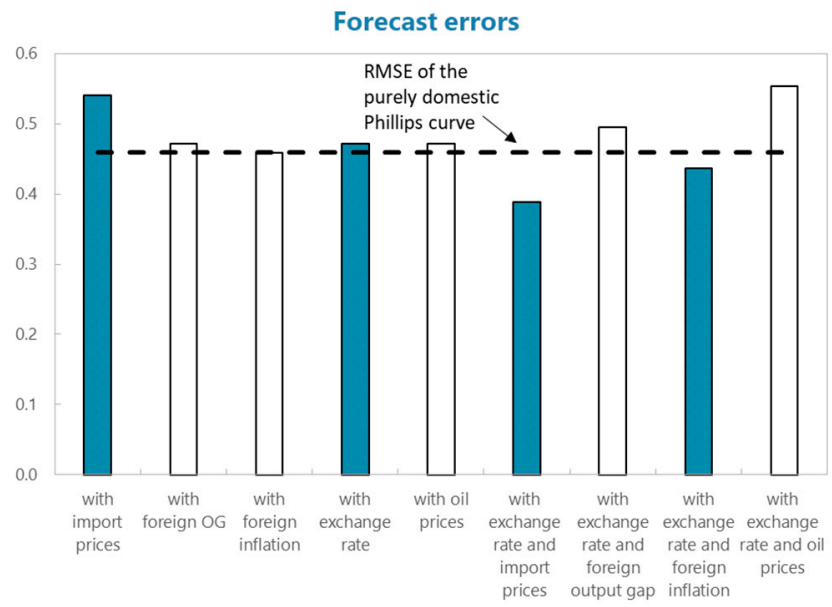

Note: Blue bars correspond to Phillips Curve specifications where global variables are selected by the GTS procedure, while white bars correspond to specifications where no global variable has been selected in the final model. Each bar illustrates the rootmean-squared-error (RMSE) of the final reduced model resulting from the GTS procedure. The dotted line corresponds to the RMSE of a purely domestic Phillips curve. A model that outperforms the domestic Phillips curve will have an RMSE lower than this threshold. 


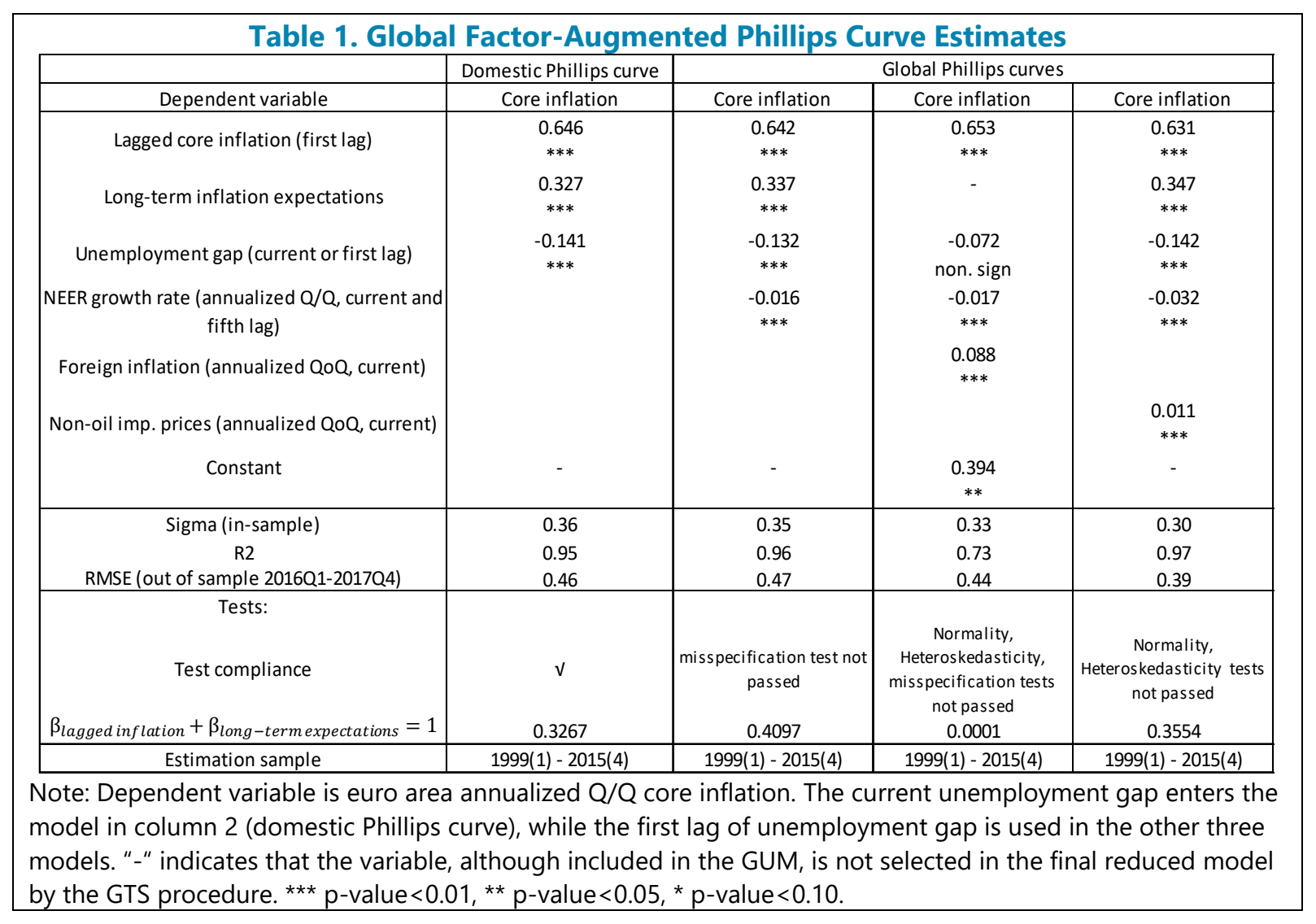

\section{Although global Phillips curves can enhance the forecasting performance of a standard domestic Phillips curve in some cases, they are found to explain recent low} inflation in a less robust way. The preferred global Phillips curve- the one that includes non-oil import prices and the exchange rate in addition to domestic variables - presents a better out-of-sample forecast performance than the domestic Phillips curve (see Appendix, Figure A.1.). However, this global Phillips curve is not satisfying from a broader point of view. First, as shown in Table 1, the in-sample goodness of fit of the estimated Phillips curves increases only to a small extent when adding these global factors, and it actually decreases considerably in the model with global inflation (probably because it results in a reduced model where forward-looking inflation expectations are not included). Second, from a technical perspective, the global Phillips curves fail to pass some standard diagnostic tests while the domestic Phillips curve does not (Table 1). ${ }^{8}$ Third, as shown in Figure 9, the key drivers for inflation dynamics are domestic factors, compared with the global factors.

\footnotetext{
${ }^{8}$ While the domestic Phillips curve model passes standard diagnostic tests, including residual autocorrelation, autoregressive conditional heteroskedasticity, normality of residuals, heteroskedasticity and general misspecification tests, this is not the case for the global factor-augmented models. Note that the statistical significance of the coefficients for the last two global Phillips curves (that do not pass heteroskedasticity tests) barely changes when considering standard errors that are robust to heteroskedasticity. Indeed, when considering robust standard errors for these two regressions where heteroskedasticity tests are not passed, the only changes occur in the second global PC specification, where the coefficient of slack becomes significant at the $10 \%$ level and the coefficient of foreign inflation significant only at the $5 \%$ level (instead of $1 \%$ ).
} 


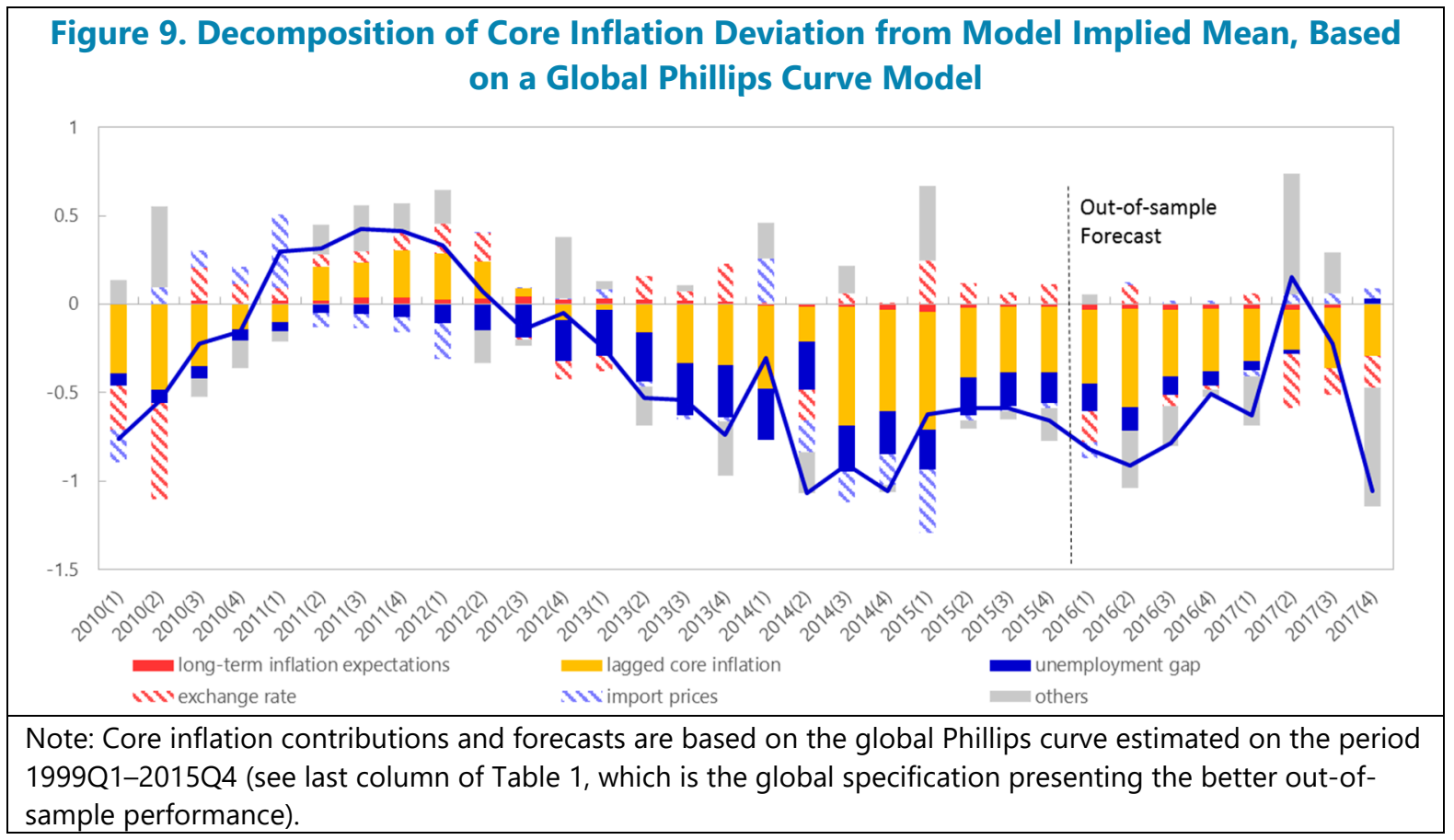

\section{The domestic Phillips curve therefore appears more robust than the global} factor augmented specifications considered. As shown in Table 1, the coefficients obtained for the domestic factors are also robust to the addition of global factors in the Phillips curve. ${ }^{9}$ For the reasons discussed above, our preferred Phillips curve for the euro area is the purely domestic one, which will be the focus in the next section.

\section{The estimated domestic Phillips} curve solves the inflation puzzle. Figure 10 shows the relationship between core inflation, net of the contribution of lagged inflation and forward-looking inflation expectations, with the unemployment gap. In contrast to Figure 2, the episodes of 2012-14 (blue dots) and 201417 (yellow dots) are consistent with the Phillips curve, stressing the importance of augmenting the Phillips curve with lagged inflation and inflation expectations, which we discuss in more details below.

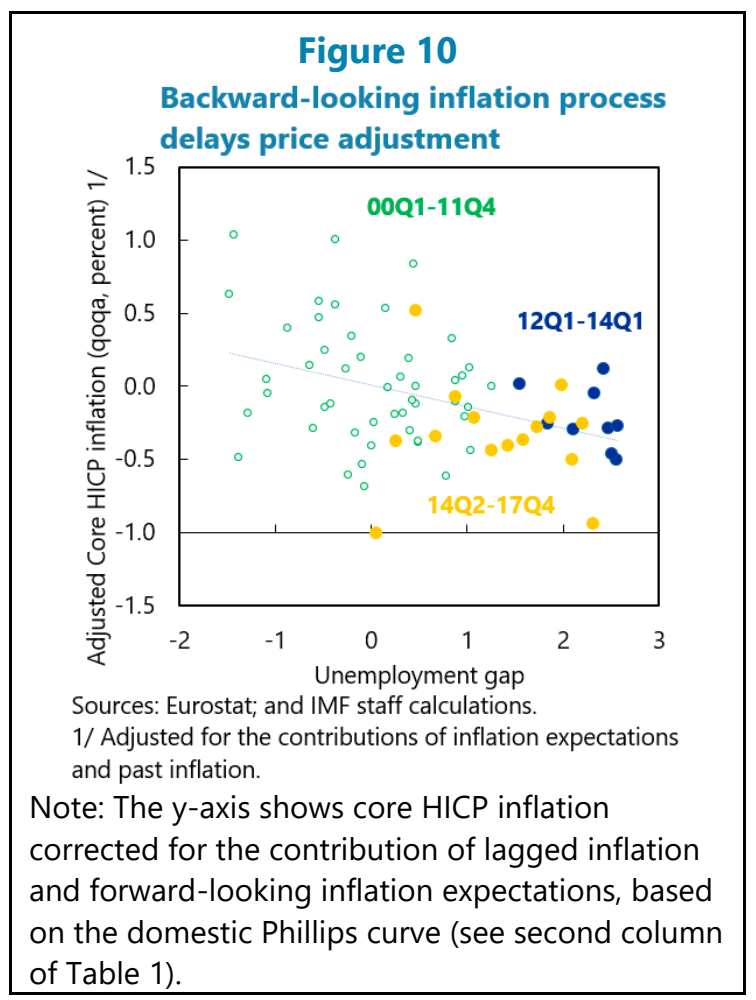

\footnotetext{
${ }^{9}$ The only exception is the coefficient of the unemployment gap in the second global specification, where the in-sample fit is weaker, probably because forward-looking expectations are not selected in the reduced model.
} 


\section{B. Which Domestic Factors Help to Solve the Inflation Puzzle?}

\section{Focusing on a purely domestic Phillips curve, we assess the robustness of our} results to alternative measures of domestic variables. We re-estimate the domestic Phillips curve specification (shown in the second column of Table 1) with different measures of slack and forward-looking inflation expectations. Besides the unemployment gap, we use the unemployment rate and the output gap as alternative measures of slack. For inflation expectations, we also use long-term and short-term inflation expectations from either ECB's Survey of Professional Forecasters or the Consensus Forecasts. ${ }^{10}$ The results are shown in Appendix, Tables A.1 and A.2.

\section{The negative relationship between inflation and slack is significant, suggesting} that the Phillips curve still works (see Appendix, Table A.1). The negative relationship stays significant when the unemployment gap is replaced by the unemployment rate as the measure of slack, with a very similar slope (-0.13, vs. -0.14 for the unemployment gap). ${ }^{11}$ This means that the result is not driven by the underlying estimate of the natural rate of unemployment. Moreover, the result is robust to substituting the unemployment gap with a non-employment gap that takes into account those who are underemployed or marginally attached to the labor force. Finally, the result also holds when different measures of output gap (IMF and OECD) are considered. For the next step of our analysis, we will use the most common specification where the unemployment gap is considered as the measure of slack. ${ }^{12}$

\section{The inflation process in the euro area appears to be backward-looking to a large} extent. As shown in Appendix, Table A.1, the coefficient on lagged core inflation is statistically significant and mostly stable at 0.6 , regardless of which measures of economic slack is used. ${ }^{13}$ This underlines the persistence in core inflation dynamics in the euro area,

\footnotetext{
${ }^{10}$ To complement this approach, we also compared the performance of our domestic baseline model (including lagged inflation, unemployment gap and long-term inflation expectations, see first column of Table 1) to other simpler models (a purely backward-looking, a model without long-term inflation expectations, a model without an unemployment gap).They turned out to be less convincing in the sense that they either do not pass the standard misspecification tests or perform worse than our baseline model on the out-of-sample window 2016Q1-2017Q4. This suggests that the slack component, as well as the forward-looking component — even if less important than the backward-looking component-do play a role in explaining inflation dynamics.

${ }^{11}$ Moreover, Chow tests on parameter constancy suggest that there is no break in the estimated coefficients of lagged inflation, inflation expectations and slack, showing that coefficients estimated on recursive subsamples have therefore stayed jointly closed to the coefficients obtained on the entire sample. This suggests that there has been no structural break in the slope of the Phillips Curve over time.

${ }^{12}$ Note that, when a constant is added to the alternative PC specifications shown in Table A.1, it is found not to be statistically significant. In these specifications, long-term inflation expectations become non-significant also, but lagged inflation and slack keep their significance, with lagged inflation and long-term inflation expectations' coefficients found to remain close to 0.6 and 0.4 respectively, and to sum to 1 .

${ }^{13}$ The estimations were based on the full sample of 1999Q1 to 2015Q4. It is not clear whether the inflation process has become more backward-looking over time. Rolling window estimations suggest that the coefficient on past inflation has increased slightly over the last 10 years, but the increase is much smaller when considering a longer time period. Moreover, as stated in footnote 11, Chow tests suggest there has been no structural break in the coefficient of past inflation over this period.
} 
which is also discussed by Ciccarelli and Osbat, 2017. Because short-term inflation expectations tend to be correlated more with lagged inflation, and the ECB's objective is meant to be achieved over the medium term rather than in the next two years, we favor longterm expectations in our main estimates. However, this result is robust also to substituting our long-term inflation expectations (five years ahead) with shorter-term inflation expectations (one or two years ahead), that could be closer to the horizon considered in a wage setting process (see Appendix, Table A.2).

\section{This, however, does not mean that inflation expectations play no role in the} inflation process. Indeed, regardless of which measure of forward-looking expectations is considered (i.e., short or long term, Consensus or from the Survey of Professional Forecasters), the coefficient on forward-looking inflation expectations remains significant, even if lower in magnitude than the backward-looking component of inflation. In fact, the goodness of fit of the model decreases sharply (from 0.95 to 0.65 ) if long-term inflation expectations are dropped from the estimation.

\section{This backward-looking feature represents a significant difference between the} inflation processes in the euro area and the U.S. In fact, when a Phillips curve is estimated for the U.S. using the same (General-to-Specific) methodology and over the same period (1999Q1 through 2015Q4), lagged core inflation does not appear to matter statistically in the inflation process (see Table 2). Instead, long-term inflation expectations are the strong attracting force for realized inflation with an estimated coefficient that is not statistically different from unity. ${ }^{14}$ The results in Table 2 clearly underscore the backward-looking inflation process as being specific to the euro area. Two additional areas of comparison are also worth noting. First, global factors seem to play a bigger role in the U.S. than in the euro area-non-oil import price growth has a larger coefficient in the U.S. Phillips curve and there is a significant loss in explanatory power in models that exclude it. And second, the coefficient on the unemployment gap - the slope of the Phillips curve - is of broadly the same magnitude in the U.S. and the euro area.

\section{Looking forward, inflation is expected to converge towards the objective, but} only gradually. Figure 11 highlights the contributions of each domestic factor to movements in core inflation. ${ }^{15}$ Euro area inflation has been driven down from 2012 onwards due to high unemployment. And these negative shocks to inflation dynamics take time to dissipate, due to the persistence of the inflation process. Note that, taking these domestic factors into account, the in-sample residuals are not consistently negative or positive, which means that the model does not systematically over- or underestimate inflation. Looking forward, the impact of tightening labor markets and closing output gaps should show up more clearly, as the effect of past negative shocks gradually fade. The reflation process should therefore

\footnotetext{
14 This dominance of expectations over persistence continues to hold, though in a somewhat weaker form, if we estimate the model starting in 1990Q1. There, both lagged inflation and long-term expectations are retained in the final reduced model, with respective coefficients of 0.23 and 0.77 -both highly statistically significant.

15 The decomposition shows that, in general, the model has a good fit with data. The relatively large forecast errors in 2017Q2 and 2017Q4 could be related to idiosyncratic factors that are not captured in the model (such as reduction in education fees in Italy and in transport insurance cost in Germany in Q4 2017).
} 
become more self-sustained. A potential increase in long-term expectations along the current trend could also contribute to the eventual convergence of core inflation towards the ECB's objective.

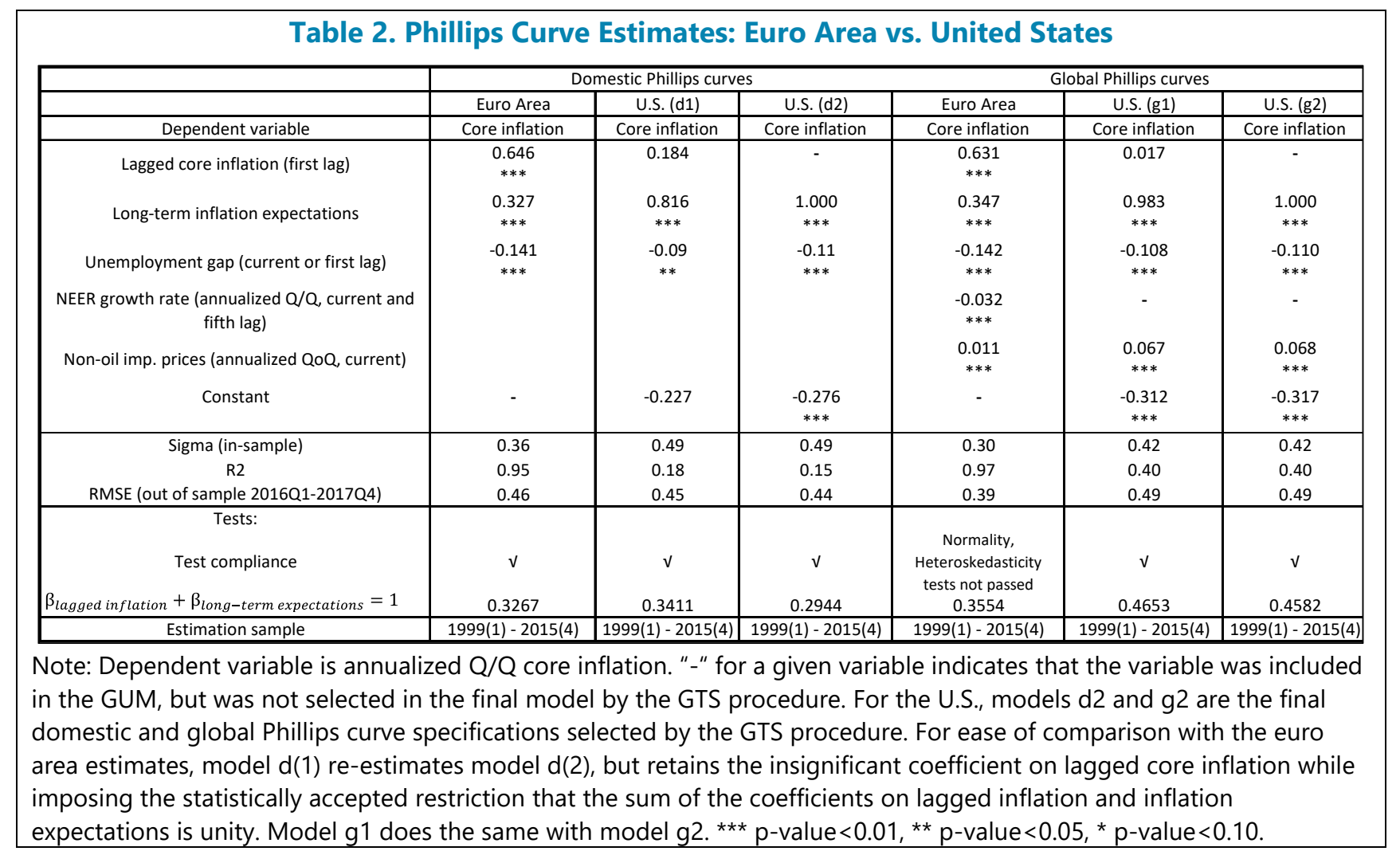

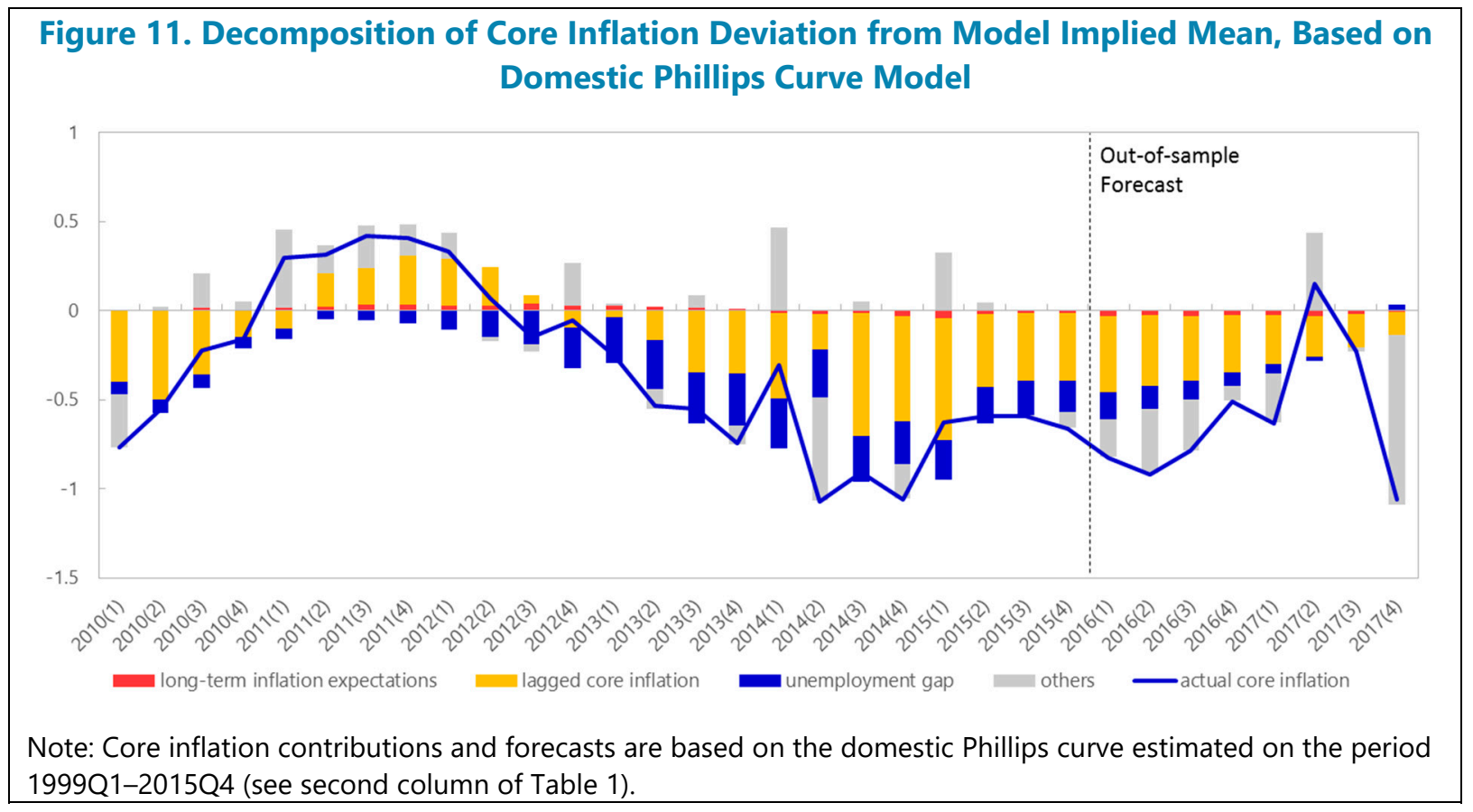

CInternational Monetary Fund. Not for Redistribution 


\section{Discussion}

Our main findings are that domestic factors dominate global factors in explaining the recent inflation dynamics and that the Phillips curve is alive and well in the euro area, with inflation persistence being the key factor behind the recent low inflation. This section discusses these results.

\section{A. On the Role of Global Factors}

\section{The finding that global slack or inflation plays a limited role could reflect that domestic inflation expectations and output gap already capture the information embedded in these global variables.}

- The domestic output gap closely follows the global output gap, due to the synchronization of the business cycle (Figure 3). As a result, the global output gap could lose its explanatory power once a domestic slack measure is included. Indeed, ECB (2017b) found that this is the case in two thirds of a broad range of Phillips curve regressions. Also, Abdih et. al. (2016) found the same result for the U.S. economy in estimated top-down and bottom-up Phillips curve models that follow the General-to-Specific approach.

- Inflation expectations by professional forecasters may incorporate information from global inflation dynamics. Mikolajun and Lodge (2016) studied the role of global inflation in domestic price developments in 19 advanced economies and found that global inflation is less helpful in explaining inflation once survey inflation expectations are controlled for, mostly because of the high correlation between the two. For example, the correlation between 5Y ahead SPF inflation expectations, which are used in our benchmark model and foreign inflation, is about 0.3 (Figure 12).

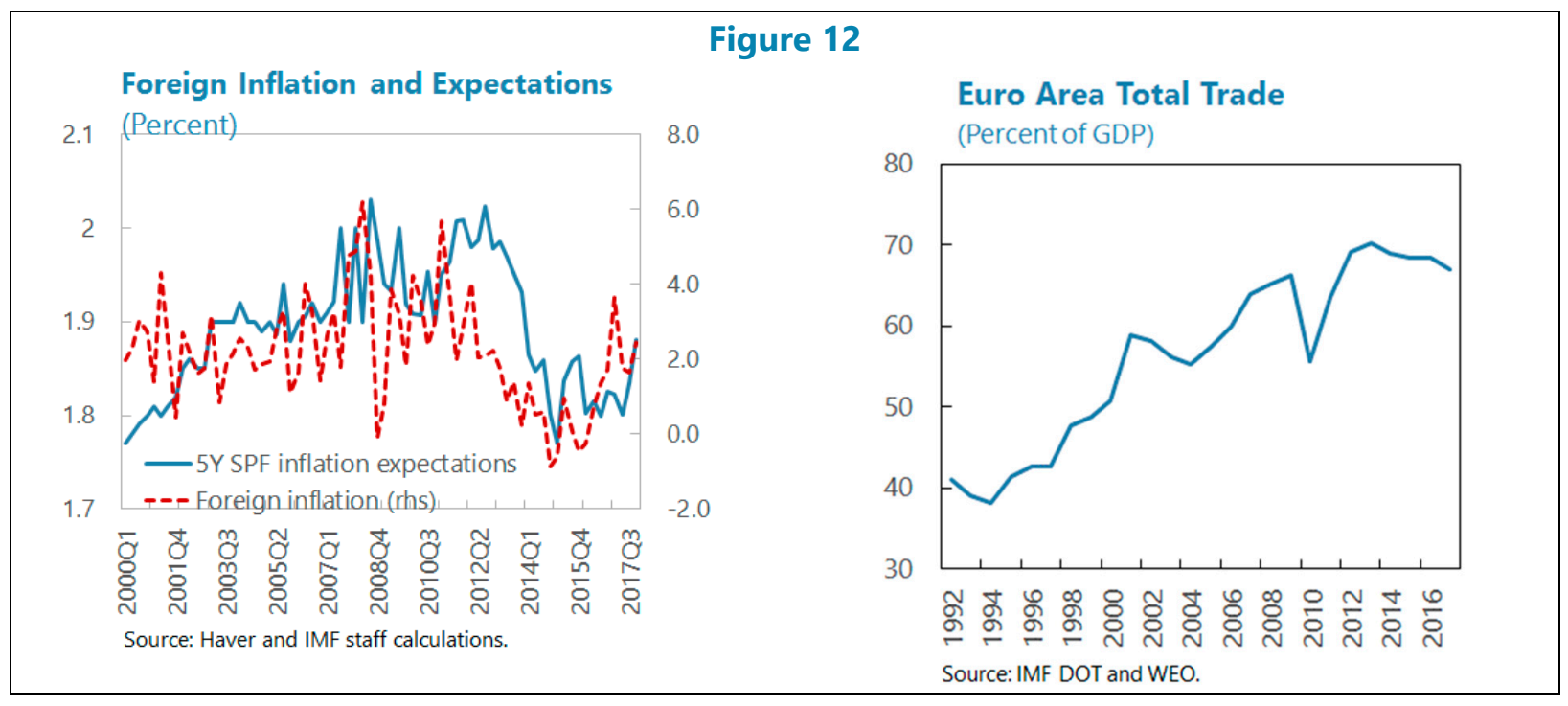

27. Our findings are also supported by the following observations: 
- First, as Ball (2006) pointed out, "there is little reason to think globalization has influenced inflation significantly." For instance, in the U.S., the greatest trade increases occurred in the 1970s - a decade notable for the absence of disinflationary forces. Similarly, in the euro area, the faster pace of trade integration with the rest of the world took place before the global financial crisis, not after (Figure 12, lhs). Therefore, should globalization be the main cause of disinflation, then we ought to have observed a low inflation phenomenon prior to the recent crisis rather than afterwards.

- Second, the double-recession, which was specific to the euro area, could be the dominant factor shaping inflation developments. As shown by Figure 13 and pointed out in ECB (2017b), core inflation has been at similar levels in the euro area and in other advanced economies during 2011-12. However, following the sovereign debt crisis, euro area inflation has moved considerably downwards and departed from developments in other OECD economies, again suggesting that its primary causes are domestic factors.

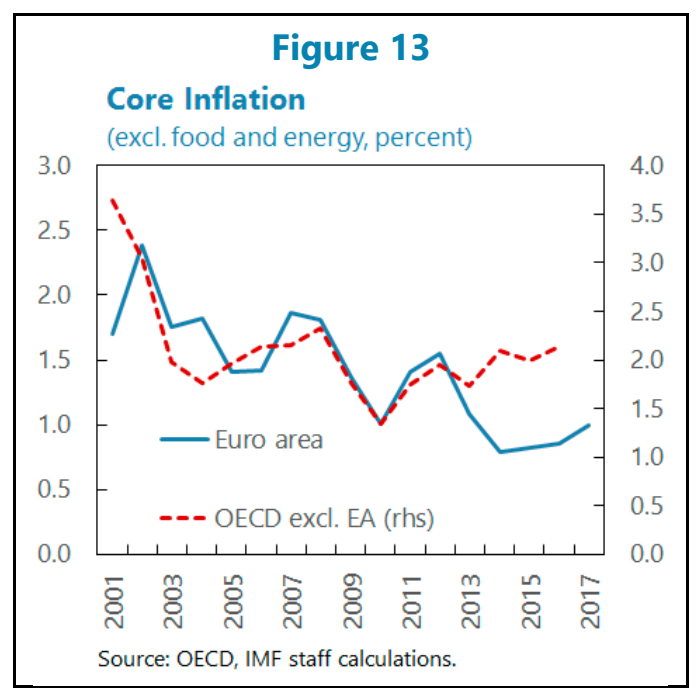

28. The limited role of exchange rate pass-through in our empirical analysis could be due to specificities of the euro area economy. The weaker role of the exchange rate in explaining price movements may reflect strong international competition, with euro area exporters forced to absorb exchange rate movements to stay competitive. ${ }^{16}$ Besides, it could also be attributed to a larger import content of exports associated with globalization, which would reduce the exchange rate effect on export prices (Di Mauro et al., 2008). Finally, the decline in the exchange rate-price link may be due to a shift in the import structure to sectors with relatively low exchange rate pass-through and to the increase in euro invoicing (with exporters deciding to absorb exchange rate movements through changing their margins, see ECB, 2016).

\section{Energy prices are likely to affect core inflation to a lesser extent than headline}

inflation. Energy prices tend to have a relatively large and immediate direct impact on headline inflation through the energy component, while its impact on core inflation is transmitted through input prices (indirect) or inflation expectations (second-round). Inflation expectations may already capture the second-round impact. This result is consistent with ECB (2010a), which found that the indirect/second-round inflation impacts of energy prices are harder to measure and estimated to be only about 0.02 . Abdih et. al. (2016) also found that oil prices do not exert a statistically significant effect on core inflation in the U.S. economy since the mid-1990s.

\footnotetext{
${ }^{16}$ This effect should be more important in sectors where exporters lack pricing power due to a high degree of competition, and where domestic goods can be easily substituted by foreign goods.
} 


\section{B. Possible Drivers of Stickier Inflation in the Euro Area (Compared to the U.S.)}

\section{While it is beyond the scope of this paper to investigate the cause of inflation persistence in the euro area, previous studies point to the following factors:}

30. Wages could be sluggish to respond to changes in underlying economic activities in the euro area, leading to stickier inflation. The slower wage adjustment could be related to the following:

- Inflation expectations embedded in agents' price- and wage-setting behaviors may be more backward- than forward-looking in the euro area. In a rational setting, inflation expectations, which are an important input of price and wage setting, should be more forward-looking, building on growth projections and the likely developments of inflation linked to the evolution of future demand. One of the euro area's specific features is the high share of SMEs, which contribute to about 60 percent of total value added in the economy, compared to 50 percent for the U.S. (ECB, 2013). SMEs may be less likely to subscribe to professional forecasters surveys and could, in this way, be constrained to consider past inflation as their best proxy for future inflation, which could contribute to the stickiness of inflation while setting new level of prices and wages. This explanation relates to Coibon et al.'s findings (2015), according to which firms tend to devote few resources to collecting and processing information about inflation. ${ }^{17}$

- Euro area labor market rigidities could also explain the slower wage growth compared to the U.S., where labor market rules are known to be more flexible (Goldman Sachs, 2018). In the euro area, the duration of wage agreements tends to be longer than in the U.S. (two years on average, vs. about one year), which could be a reason why wages are reset less frequently, leading to more persistent inflation. Besides, wage changes are found to be more likely for workers who switch jobs as opposed to those who stay in the same firm (see Barattieri et al., 2014). Lastly, wage indexation to inflation is less prevailing in the euro area than in the U.S. (around 35 percent of wage contracts, vs. around 50 percent, see ECB, 2010b). This corroborates with Taylor (2016), who suggests that U.S. wages are reset more frequently than euro area wages.

31. Finally, the transmission of labor market developments to prices ultimately depends on the pricing power of firms, which contributes to determining how frequently prices are adjusted. Barriers to price adjustment could be linked to long-term relationships with customers, stricter product market regulations or the degree of competition in the product market. Although it is not clear which factors play the bigger role, these aspects could also explain some of the differences in inflation stickiness between the euro area and the U.S. (Álvarez et al., 2005, Altissimo et al., 2006, Goldman Sachs, 2018). It would be an interesting area for future research.

\footnotetext{
17 The authors' survey includes both small- and medium-sized firms.
} 


\section{On the Anchoring of Inflation Expectations}

\section{Inflation persistence is not necessarily due to backward-looking inflation} expectations. Some studies point to inflation expectations being driven less by forwardlooking expectations than by past inflation (Fuhrer, 1997, Rudd and Whelan, 2005). However, as suggested in the previous section, other factors such as labor market rigidities or features related to the pricing power of firms could also be at the origin of inflation persistence.

\section{In the case of the euro area, inflation expectations by professional forecasters} and market participants have not sustainably deviated from the ECB's inflation objective. A sequence of deflationary shocks could contribute to de-anchoring inflation expectations through a reduction of the perceived inflation target (Busetti et al., 2017). However, long-term inflation expectations from the survey of professional forecasters have been relatively stable over time and are now back to 1.86 percent (after reaching a bottom of 1.77 percent in Q1 2014, see Figure 14). Market-based inflation expectations, which also incorporate a compensation for inflation and liquidity risk premia (Grothe and Meyler, 2015) and tend to be more volatile, have also undertaken an upward trend after bottoming at around 1.3 percent in mid-2016. They are now back to close to 1.8 percent. Therefore, even if inflation expectations had declined over the recent past, they seem to be recovering gradually towards the ECB's inflation objective of below but close to 2 percent.

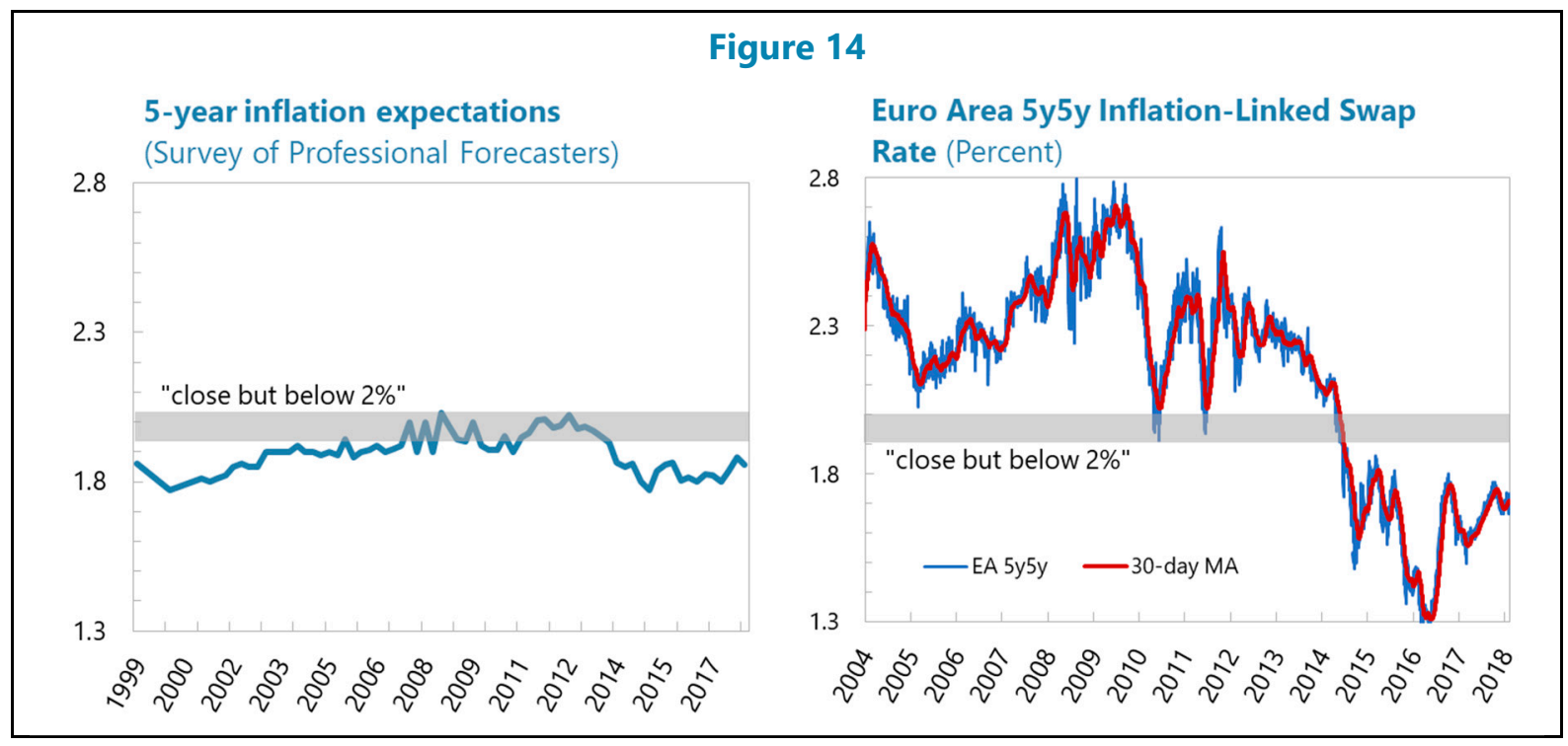

\section{Policy Implications ANd Conclusion}

\section{Convergence of core inflation towards the ECB's medium-term objective is}

likely to be gradual. Despite the recent reduction in labor market slack, core inflation in the euro area has remained largely subdued. Our empirical analysis has shown that this is not due to disinflation elsewhere or other global factors. Rather, low inflation outcomes have been largely the result of inertia and high persistence in the inflation process, which has countered the gravitational force of inflation towards the medium-term objective. 
35. This makes the case for continued strongly accommodative monetary policy. It is needed to support higher inflation, through both stronger demand and anchored inflation expectations. A premature tightening could quickly undo the slow process of price adjustment, with long-lived consequences.

\section{The ECB is correct to emphasize that interest rates will remain low well beyond the end of net asset purchases. This strong forward guidance should not be changed until the performance of actual inflation supports it or there is a firm assessment that the inflation outlook has improved decisively. The primarily backward-looking nature of the inflation process reinforces the relevance of forward guidance by making it imperative to look through temporary upward shifts in inflation. Therefore, the ECB's guidance on keeping the monetary policy stance accommodative for an extended period is crucial. It will play on forward-looking expectations, which — although not preponderant — are still a significant factor of the domestic Phillips curve, therefore guiding future inflation. Moreover, forward guidance contributes to easy financial conditions, thereby providing support to inflation through real activity.}




\section{APPENDIX}

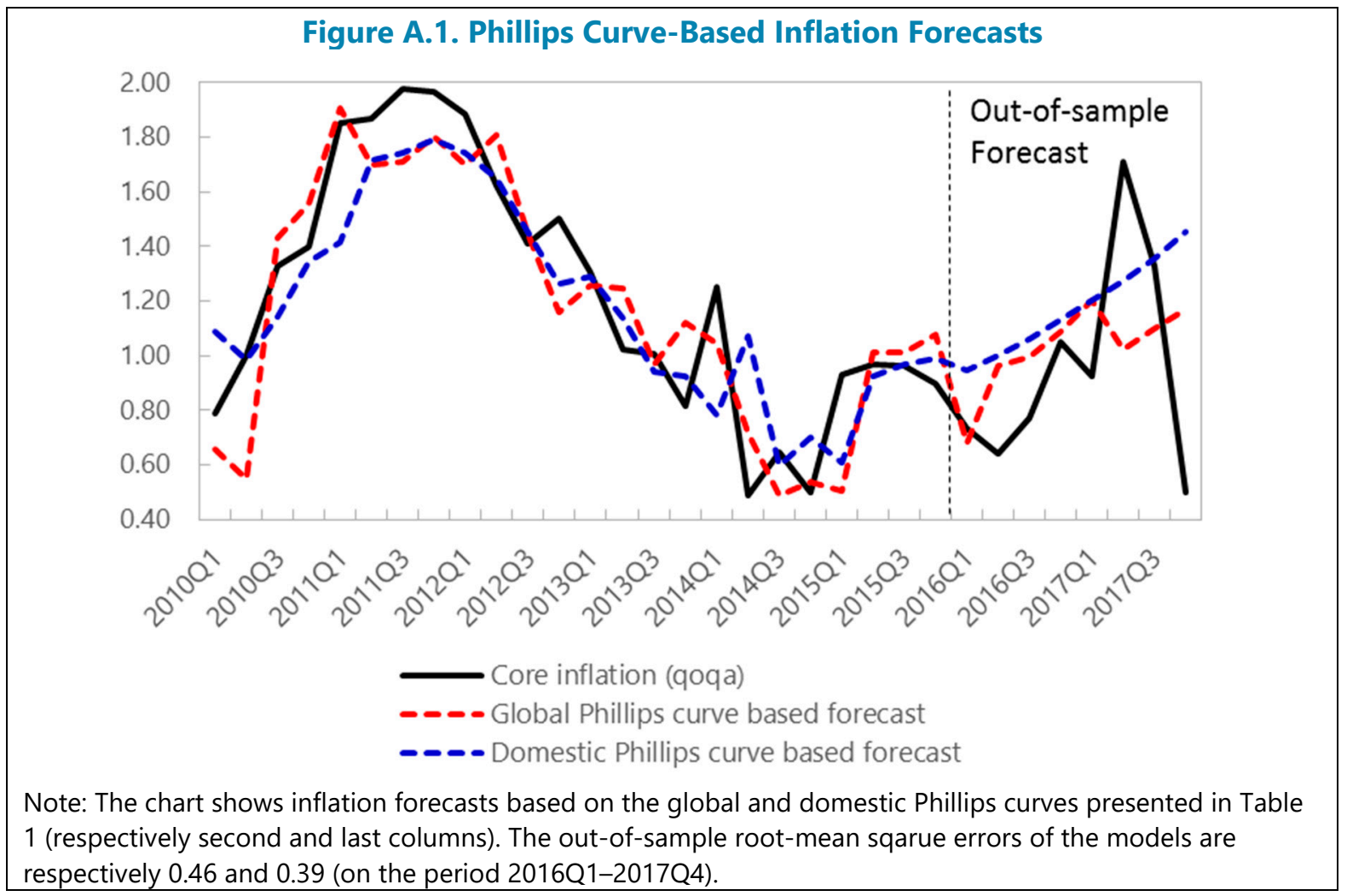

\begin{tabular}{|c|c|c|c|c|c|}
\hline & $\begin{array}{c}\text { unemployment } \\
\text { gap }\end{array}$ & u & IMF OG & OECD OG & NE_gap \\
\hline Dependent variable & Core inflation & Core inflation & Core inflation & Core inflation & Core inflation \\
\hline Lagged core inflation (first lag) & $\begin{array}{c}0.646 \\
* * *\end{array}$ & $\begin{array}{c}0.614 \\
* * *\end{array}$ & $\begin{array}{c}0.617 \\
* * *\end{array}$ & $\begin{array}{c}0.619 \\
* * *\end{array}$ & $\begin{array}{c}0.672 \\
* * *\end{array}$ \\
\hline Long-term inflation expectations (SPF) & $\begin{array}{c}0.327 \\
* * *\end{array}$ & $\begin{array}{l}0.953 \\
* * *\end{array}$ & $\begin{array}{c}0.327 \\
* * *\end{array}$ & $\begin{array}{c}0.335 \\
* * *\end{array}$ & $\begin{array}{c}0.269 \\
* * *\end{array}$ \\
\hline slack (current) & $\begin{array}{c}-0.141 \\
* * * \\
\end{array}$ & $\begin{array}{c}-0.127 \\
* * * \\
\end{array}$ & $\begin{array}{c}0.103 \\
* * * \\
\end{array}$ & $\begin{array}{c}0.088 \\
* * * \\
\end{array}$ & $\begin{array}{c}-0.333 \\
* * \\
\end{array}$ \\
\hline sigma (in-sample) & 0.36 & 0.36 & 0.35 & 0.35 & 0.37 \\
\hline R2 & 0.95 & 0.95 & 0.96 & 0.96 & 0.95 \\
\hline RMSE (out of sample 2016Q1-2017Q4) & 0.46 & 0.46 & 0.43 & 0.45 & 0.75 \\
\hline $\begin{array}{c}\text { Tests: } \\
\text { Test compliance } \\
\beta_{\text {lagged inflation }}+\beta_{\text {long-termexpectations }}=1 \\
\end{array}$ & $\begin{array}{c}V \\
0.3267 \\
\end{array}$ & $\begin{array}{c}V \\
0.0095 \\
\end{array}$ & \begin{tabular}{|c|} 
heteroskedasticity \\
test not passed \\
0.0359 \\
\end{tabular} & $\begin{array}{c}V \\
0.0845 \\
\end{array}$ & \begin{tabular}{|c} 
heteroskedasticity \\
test not passed \\
0.0417
\end{tabular} \\
\hline Estimation sample & 1999(1) - 2015(4) & 1999(1) - 2015(4) & 1999(1) - 2015(4) & 1999(1) - 2015(4) & 1999(1) - 2015(4) \\
\hline \multicolumn{6}{|c|}{$\begin{array}{l}\text { Note: The table shows variants of the domestic Phillips curve shown in Table } 1 \text { (first column). Here, the } \\
\text { estimates shown in the different columns only differ in the measure of slack considered in the specification of } \\
\text { the Phillips curve (respectively unemployment gap, unemployment rate, IMF and OECD output gaps, and non- } \\
\text { employment gap). The non-employment gap is constructed as the difference between the four-quarter } \\
\text { moving average of the euro area non-employment index and its HP filter-based trend. Note that in the last } \\
\text { column, the out-of-sample RMSE is computed on the period 2016Q1-2017Q2. } \\
{ }_{* * *} \text {-value }<0.01,{ }^{* *} p \text {-value }<0.05,{ }^{*} p \text {-value }<0.10 \text {. }\end{array}$} \\
\hline
\end{tabular}




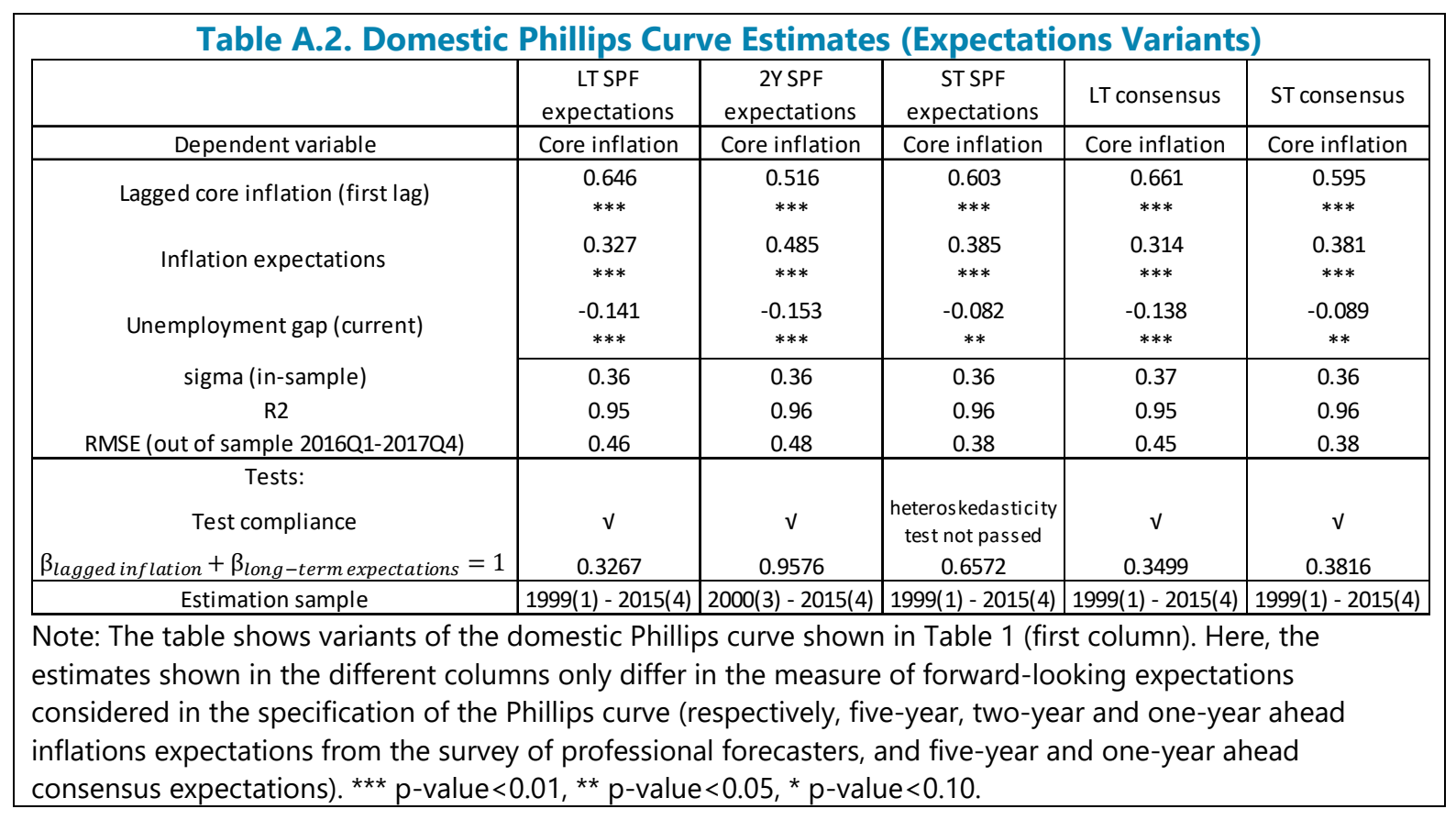




\section{REFERENCES}

Abdih, Y., Danninger, S., 2018, "Understanding U.S. Wage Growth,” IMF Working Paper No. 18/138 (Washington: International Monetary Fund).

Abdih, Y., Balakrishnan, R., Shang, B., 2016, "What is Keeping U.S. Core Inflation Low: Insights from a Bottom-up Approach," IMF Working Paper No. 16/124.

Altissimo, F., Ehrmann, M., and Smets, F., 2006, "Inflation Persistence and Price-setting Behavior in the Euro Area: A Summary of the IPN Evidence," ECB Occasional Paper No. 46 (Frankfurt: European Central Bank).

Álvarez, L., Dhyne, E., Hoeberichts, M., Kwapil, C., Le Bihan, H., Lünnemann, P., Martins, F., Sabbatini, R., Stahl, H., Vermeulen, P., and Vilmunen, J., 2005, "Sticky Prices in the Euro Area, A Summary of New Micro Evidence," ECB Working Paper No. 563 (Frankfurt: European Central Bank).

Auer, R., Borio, C., Filardo, A., 2017, The Globalisation of Inflation: The Growing Importance of Global Value Chains. Bank for International Settlements Working Papers, No. 602.

Ball, L., 2006, “Has Globalization Changed Inflation?” NBER Working Paper No. 12687 (Cambridge, Massachusetts: MIT Press).

Barattieri, A., Basu, S., Gottschalk, P., 2014, "Some Evidence on the Importance of Sticky Wages," American Economic Journal: Macroeconomics, Issue 6(1), pp. 70-101.

Busetti, F., Delle Monache, D., Gerali, A., Locarno, A., 2017, “Trust, but Verify. Deanchoring of Inflation Expectations Under Learning and Heterogeneity,” ECB Working Paper No. 1994 (Frankfurt: European Central Bank).

Calza, A., 2008, “Globalisation, Domestic Inflation and Global Output Gaps-Evidence from the Euro Area," ECB Working Paper No. 890 (Frankfurt: European Central Bank).

Campos, J., Ericsson, N. R., Hendry, D. F., 2005, "General-to-Specific Modeling: An Overview and Selected Bibliography," Board of Governors of the Federal Reserve System International Finance Discussion Papers, No. 838.

Carney, M., 2017, [De]Globalisation and Inflation. Speech at the 2017 IMF Michel Camdessus Central Banking Lecture (September 18).

Ciccarelli, M., Osbat, C., 2018, "Low Inflation in the Euro Area: Causes and Consequences," ECB Occasional Paper No. 181 (Frankfurt: European Central Bank).

Coibon, O., Gorodnichenko, Y., Kumar, S., 2015, "How Do Firms Form Their Expectations? New Survey Evidence," American Economic Review, forthcoming. 
Di Mauro, F., Ruffer, R., and Bunda, I., 2008, "The Changing Role of Exchange Rate in a Globalized Economy,” ECB Occasional Paper No. 94 (Frankfurt: European Central Bank).

European Central Bank, 2010a, Oil Prices-Their Determinants and Impact on Euro Area Inflation and the Macroeconomy, p. 75, Article (August).

European Central Bank, 2010b, Wage Developments in the Euro Area and the United States During the Recent Economic Downturn: A Comparative Analysis, Monthly Bulletin, Box 8 (May).

European Central Bank, 2011, Inflation in the Euro Area and the United States: An Assessment Based on the Phillips Curve, Monthly Bulletin, Box 1 (June).

European Central Bank, 2013, Small and Medium-sized Enterprises in the Euro Area:

Economic Importance and Financing Conditions, Economic Bulletin, Box 6, Issue 2, 2013.

European Central Bank, 2016, Exchange Rate Pass-through into Euro Area Inflation, Economic Bulletin, Article 1, Issue 7.

European Central Bank, 2017a, Assessing Labor Market Slack. Economic Bulletin, Article 3, Issue 3.

European Central Bank, 2017b, Domestic and Global Drivers of Inflation in the Euro Area, Economic Bulletin, Article, Issue 4.

European Central Bank, 2018, Speech by Mario Draghi, President of the ECB, The ECB and its Watchers XIX Conference organized by the Institute for Monetary and Financial Stability, Frankfurt (March 14).

Fuhrer J., 1997, "The (Un)Importance of Forward-looking Behavior in Price Specifications," Journal of Money, Credit, and Banking, Vol. 28, No. 3.

Gali J., Gertler, M., 1999, "Inflation Dynamics: A Structural Econometric Analysis," Journal of Monetary Economics, Volume 44, Issue 2, p. 195.

Goldman Sachs, 2018, "Product and Labour Market Liberalization Reforms Reduce the Persistence of Inflation," Goldman Sachs European Views.

Grothe M., Meyler, A., 2015, "Inflation Forecasts: Are Market-based and Survey-based Measures Informative?" ECB Working Paper No. 1865 (Frankfurt: European Central Bank).

International Monetary Fund, 2017a, "What is Behind the Euro Appreciation Against the U.S. Dollar Since Early 2017?” IMF European Regional Economic Outlook, Chapter 1 (October).

International Monetary Fund, 2017b, "Recent Wage Dynamics in Advanced Economies: Drivers and Implications," IMF World Economic Outlook, Chapter 2 (October). 
International Monetary Fund, 2018, "European Wage Dynamics and Labor Market Integration,” IMF European Regional Economic Outlook, Chapter 2 (April).

Mikolajun I., Lodge, D., 2016, "Advanced Economy Inflation: The Role of Global Factors," ECB Working Paper No. 1948 (Frankfurt: European Central Bank).

Rudd J., Whelan, K., 2005, "New Tests of the New-Keynesian Phillips Curve," Journal of Monetary Economics, No. 52.

Taylor, J., 2016, "The Staying Power of Staggered Wage and Price Setting Models in Macroeconomics," NBER Working Paper No. 22356 (Cambridge: Massachusetts: MIT Press). 